\title{
Spatiotemporal Landuse Land Cover Changes in Walmara District, Central Oromia, Ethiopia
}

\author{
Tokuma Urgessa*, Debissa Lemessa \\ Department of Forest and Range Land Plant Biodiversity, Ethiopian Biodiversity Institute, Addis Ababa, Ethiopia \\ Email address: \\ tokeurgessa@gmail.com (T. Urgessa), lemdeb@yahoo.com (D. Lemessa) \\ ${ }^{*}$ Corresponding author \\ To cite this article: \\ Tokuma Urgessa, Debissa Lemessa. Spatiotemporal Landuse Land Cover Changes in Walmara District, Central Oromia, Ethiopia. Earth \\ Sciences. Vol. 9, No. 1, 2020, pp. 32-37. doi: 10.11648/j.earth.20200901.14
}

Received: August 8, 2019; Accepted: October 15, 2019; Published: January 17, 2020

\begin{abstract}
The rapidly changing landuse/landcover at various scales mainly during the past recent decades have caused the degradation of biodiversity and this in turn has affected the human wellbeing in Ethiopia. However, adequate study is lacking particularly in Walmara district where intensive cereal based faming system is exerted by the rapidly increasing rural population growth. Hence, the aim of this study was to examine the spatiotemoral pattern of the landuse/landcover change that has taken place in 1985 and in 2017 . For this, two Landsat images $(30 \times 30 \mathrm{~m}$ resolution) were used to analyze temporal landuse/landcover changes with the application of Geographic information system (GIS) techniques and remote sensing (RS) using Quantum GIS (version: 2.18). Here, a supervised image classification technique was applied with Maximum likelihood classification algorism. With this analysis six main landuse/land cover types namely, cropland, grassland, forest land, settlement, wetland and water body were identified. In 1985 the areas of cropland (52816ha), grass land (16755ha), forest land (4633ha), wetland (1665ha), settlement (1124ha) and waterbody (125ha), while in 2017, the areas of cropland (64984ha), grass land (2442), forest land (4329ha), wetland (1404ha), settlement (3790ha) and waterbody (170ha). These results show that over the last thirty years, in the study district, the area covered by crops has increased by $15.8 \%$, settlement area by $3.5 \%$ while, in contrast, the areas covered by grassland has shrunk by $18.6 \%$, forest area by $0.4 \%$ in 2017 . The major reasons for such rapid changes in landuse/landcover in the study are land exploration for agricultural purpose and built ups for settlement and small scale factories. Overall, the present finding suggest the essence of devising integrated landuse policy and plan to sustainably utilize the limited land and land resources and to reduce the impact of climate change that is occurring mainly due to the unwise use of these resources.
\end{abstract}

Keywords: Walmara District, Landsat, QGIS, Land Use Land Cover, Supervised Classification

\section{Introduction}

Landuse/landcover change (LULCC) refers to the earth's territorial surface modification by human activities [2]. Change is nearly inseparable from human activities and use, and the main aim is to encourage enhancement and counter forces that encourage dilapidation [9].

Though Human beings have been modifying natural environments to obtain short term solution for their problems for several thousands of years, the rates, extents and intensities of human pressure on land is by far greater than ever before. Such dramatic rate of land use land cover change is affecting the status, properties and functions of ecosystems, which in turn affect the provision of ecosystem services and hence human well-being [7].

Likewise of other countries in the world though LULCC is not a recent phenomenon in Ethiopia [12], it is exacerbated by the scale, speed and long-term nature of urbanization and modernization [16]. These changes are mainly from natural vegetation land to agricultural land and non-vegetative land use in which settlement and degraded land uses are among. Different studies have been conducted to quantify land use land cover change in both highland and low-land parts of Ethiopia [6, 13, 15, 18, 21]. According to these studies, Ethiopia is characterized by a reduction of forest, woodlands, grasslands, and shrub lands, but a remarkable expansion of agricultural land and bare lands in space and time. The highland areas in Ethiopia cover nearly $45 \%$ of the country's 
landmass [16].

The Ethiopian highlands in which Walmara woreda among are the most densely populated and it is also categorized as agricultural areas and as a result intense land use land cover changes including the protected areas have been recording.

The land use land cover change problem is more severe in the highlands of Ethiopia [8]. It is because these areas were characterized by high population pressure and cultivated for long period of time [13].

\section{Methods}

\subsection{Study Area}

The study was carried out at Walmara district which is situated between the geographical coordinates $8^{\circ} 5^{\prime}-9^{\circ} 51^{\prime} \mathrm{N}$ and $38^{\circ} 25^{\prime}-38^{\circ} 45^{\prime} \mathrm{E}$ in Oromia national regional state, at about $40 \mathrm{~km}$ southwest of Addis Ababa city, central Ethiopia at about (figure 1).

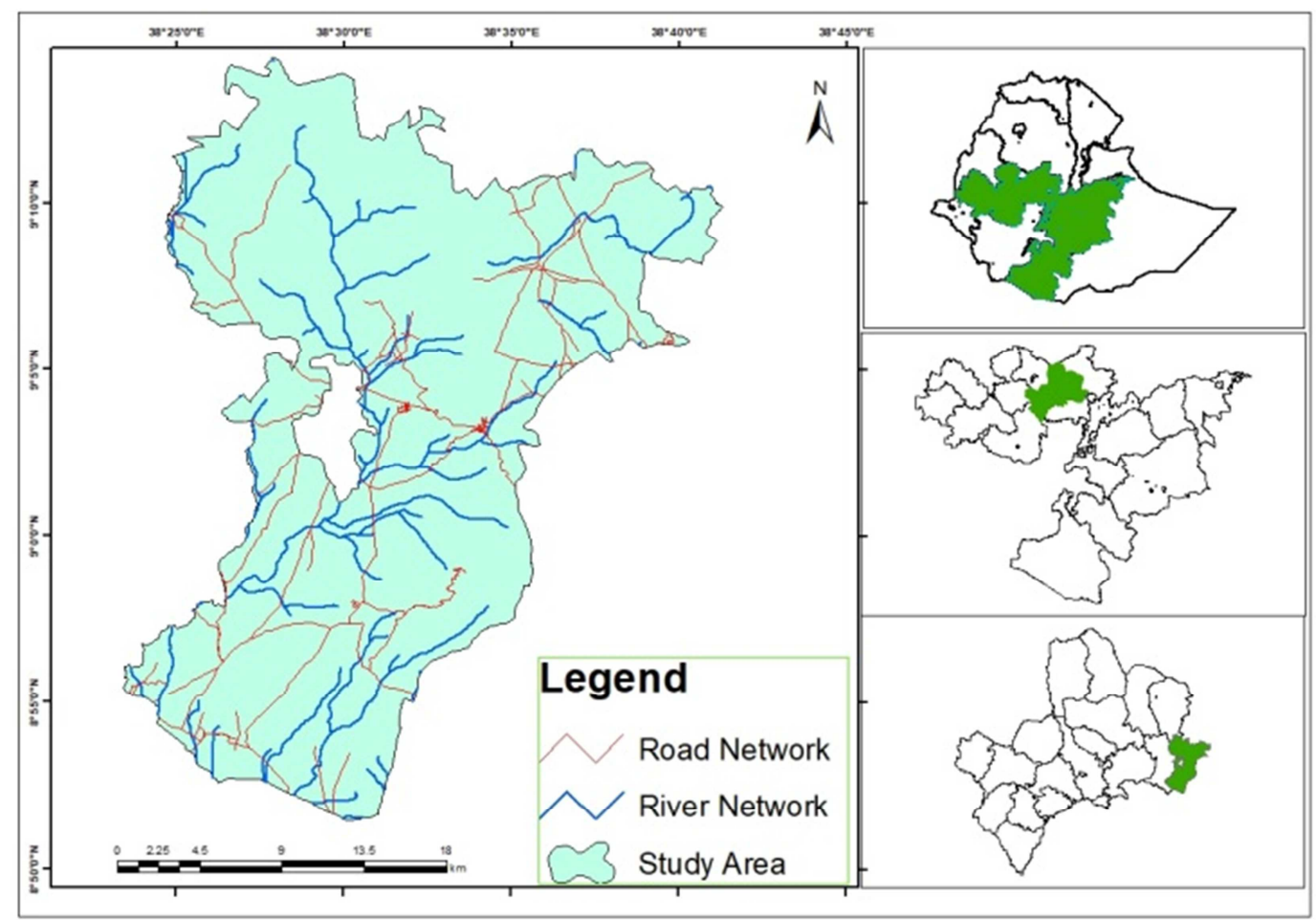

Figure 1. Map of the study area and its relative location in terms of the maps of Oromia regional state and Ethiopia.

\subsection{Image Acquisition}

Different sensors of the Landsat images, $(30 \mathrm{~m} \times 30 \mathrm{~m}$ resolution) of 1985 and 2017 were downloaded from US Geological Survey website (https://earthexplorer.usgs.gov/). These Thematic Mapper (TM) and Operational Land Imager (OLI) were used to assess the pattern and extent of land use/land cover change of the district between 1985 and 2017 after being mosaicked and preprocessed.

Hereby, mosaic of two satellite images of the same season and the same year were used for change detection analysis. The two imageries used for mosaicking were with a different path numbers (168 \& 196) and with the same raw number "054" and the study area was defined by clipping the satellite images to shape file of the district (Table 1). Moreover, the ground truth points were collected using the Geographical Positioning System (GPS) in the same season corresponding to the imageries used for the 2017 and from google earths and information from the elder people for 1985 .

Table 1. Basic characteristics of the land sat images used for the study.

\begin{tabular}{lllllll}
\hline Producer & Sensor & Resolution & Cloud cover & Acquisition date & Path/raw & year \\
\hline USGS & TM & $30 \mathrm{~m} \times 30 \mathrm{~m}$ & 0.00 & $19850102 \& 19851109$ & $168054 \& 169054$ & 1985 \\
USGS & OLI & $30 \mathrm{~m} \times 30 \mathrm{~m}$ & 0.00 & $20171212 \& 20171203$ & $168054 \& 169054$ & 2017 \\
\hline
\end{tabular}

Date format: YY/MM/DD.

\subsection{Image Preprocessing}

Image Preprocessing is a technique which is used to enhance raw images received from cameras and sensors placed on satellites, space probes and aircrafts or pictures taken in normal day-today life for various applications.
Image preprocessing according to Coppin and Bauer, is commonly comprises a series of sequential operations, including radiometric normalization, image layer stacking, image registration, geometric and atmospheric correction with Dark Object Subtraction (DOS1) and masking of clouds, 
water and irrelevant features [4].

Accordingly the preprocessing activities including merging of different bands, sub-setting, image enhancement and atmospheric correction with (DOS1) were done to both images of 1985 and 2017 prior to clipping and mosaicking the images to the district area.

After all the images were corrected in the same way, all scenes from the same year were mosaicked together so that fit to the extent of study area. From the mosaicked image, the portion that was felt within the study area was clipped to limit the size of the image to the size of the study area for which preliminary classification, field verification, and the processing work were done at a later stage.

\subsection{Image Classification}

Image classification is the process of assigning land cover classes to pixels [1]. According to $\mathrm{Lu}$ and Weng, there are three main image classification techniques in general which may include unsupervised, supervised and object based methods [14]. Supervised classification according to Eastman, is where "the user develops one or more spectral signatures of known land use categories, such as settlement, crop, water body, wetland and forest, with the help of Semi-Automatic Classification Plugin (SCP) for QGIS and then the software assigns each pixel in the image to a particular cover type to which its signature is most comparable [5]. Richards and Jia, argued that "supervised classification is the process most frequently used for quantitative analyses of remote sensing image data" [17].

For this study, supervised classification with Maximum Likelihood Classification (MLC) algorithm was performed with sequential steps, including training area selection, Generating of signature file for the training areas which were in vector/polygon forms and Classification was done at the end.

During the satellite imagery classification both visual and digital image interpretation were used. Using visual cues, such as tone, texture, shape, pattern, and relationship to other objects, an observer can identify many features in an image.

\subsection{Post Classification and Accuracy Assessments}

Accuracy assessment is commonly done with reference to other images [11, 19]. Unless and otherwise accuracy assessment is done to an image classification it limits the confidence of the result. Thus, accuracy assessments of the classified images were done by taking 60 random points. The points were traced using GPS and identified their past Land Cover class from the knowledge of elder people. Finally the error matrix system has been used to compare the ground truth with the classified land cover classes. This was done to both classified satellite images (TM and OLI). A total of 300 ground control points (GCPs) and 50 GCPs for each land use were collected from field between 10:00 a.m. and 4:00 p.m. and of these ground control points, $60 \%$ (180) were used for the classification while $40 \%$ (120) were used for validation assessment to the classification done.

\subsection{Data Analysis}

The spatial and temporal landuse/landcover classification and change were analyzed using Quantum Geographical Information System. In addition to this analysis, secondary information about the landuse/landcover of the district was also referred in Google earth engine, Bing maps and topo map sheet.

A supervised classification with Maximum Likelihood Classification (MLC) algorithm was performed with sequential steps, including training area selection and generation of signature file for the training areas. Along with this digital image classification, visual interpretation was performed based tone, texture, shape, pattern and relationship to other objects or features in an image.

Moreover, field observation was made to confirm the classified images with the land use types on the ground and finally six major land use/land cover types including cropland, grassland, forest land, wetland, water body and settlement areas were identified. Based on the classification system adapted by UNFCCC (2017) landuse-landcover types were described as indicated below (Table 2).

Table 2. Classification scheme for major land use land cover of the district.

\begin{tabular}{ll}
\hline Water body & Area occupied by major rivers of perennial or Intermittent, lakes, ponds and reservoirs \\
\hline Wetland & $\begin{array}{l}\text { Area dominated by wetland herbaceous vegetation or are non-vegetate where the water table is at, near, or above the land surface for a } \\
\text { significant part of most years dominantly including the wet prairies, and open bogs }\end{array}$ \\
$\begin{array}{l}\text { Crop land } \\
\text { Settlement }\end{array}$ & $\begin{array}{l}\text { Arable and fallow land that grow annual crops or perennial crops on the small scale or commercial level by rain fed or irrigate schemes } \\
\text { Comprised of built up areas and commercial complexes, and institutions that may in some cases isolated from urban areas. }\end{array}$ \\
Grassland & $\begin{array}{l}\text { Land covered with the natural growth of graminea and herbaceous vegetation or a land sown with introduced grass and leguminous for } \\
\text { grazing of livestock. }\end{array}$ \\
Forest & $\begin{array}{l}\text { Aland spanning at least } 0.5 \text { ha cover attaining a height of at least } 2 \mathrm{~m} \text { and a canopy cover of at least } 20 \% \text { or trees with potential to these } \\
\text { thresholds in situ in due course, this forest definition is in the light of the varied forest type and potential of carbon stock in the country }\end{array}$ \\
\hline
\end{tabular}

To enhance the accuracy of the classification, several measures of accuracy assessment such as, producer accuracy, user accuracy and overall accuracy were applied to the multitemporal images used for the study. The classified images were compared with the reference images by means of confusion matrix tabular data.

\subsection{Change Detection}

Post-classification comparison was made in which the classification results were produced from two images acquired in different time periods and subsequent comparison of pixel-by-pixel was operated. Post-classification 
comparison method minimizes associated problems with multi-temporal images that are recorded under different atmospheric and environmental conditions.

The method offers also an advantage of representation of nature, of occurring changes and it compares classifications of images from different dates and it separately classifies the data from different dates, and thus, this multi-date data does not require any adjustment for direct comparison. The Area in hectares of the resulting land use/land cover change was calculated for both 1985 and 2017 periods and subsequently compared. The accuracy assessment of the multi-temporal classified images, area of change [6] and percentage of change were computed to demonstrate the magnitude of the changes experienced between the two periods [3,21].

\section{Result}

Six major landuse/land cover types were identified from the satellite image analysis in Walmara district (Figure 1). These landuse/Land cover types include crop land, grassland, forest land, wetland, water body and settlement (Table 3). Crop land was distinctly noticeable with its dominance area coverage of 52816ha followed by grass land, forest land, wetland and settlement with 16755, 4633, 1665 and 1124 are in hectar respectively (table 3 ). In the past thirty two years, crop land has increased by $15.8 \%$ and settlement area by $3.5 \%$, while, in contrast, the landuse types covered by grassland has shrunk by $18.6 \%$ and forest by $0.4 \%$ in 2017 (Table 3).


Figure 2. The major landuse/landcover of Walmara district identified from the satellite image analysis taken in 1985 and 2017. The overall accuracy of the classification is 89\% in 1985 and $84 \%$ in 2017.

Table 3. Area coverage and percentage constitutes of major land use land cover of Walmara district in1985 and 2017.

\begin{tabular}{lllllll}
\hline Land uses & $\mathbf{1 9 8 5}$ & $\mathbf{2 0 1 7}$ & Change (ha) & $\mathbf{1 9 8 5 \%}$ & $\mathbf{2 0 1 7 \%}$ & change \% \\
\hline Crop Land & 52816 & 64984 & 12168 & 68.49 & 84.27 & 15.8 \\
Grass Land & 16755 & 2442 & -14314 & 21.73 & 3.17 & -18.6 \\
Forest Land & 4633 & 4329 & -304 & 6.01 & 5.61 & -0.4 \\
Wet Land & 1665 & 1404 & -261 & 2.16 & 1.82 & -0.3 \\
Water Body & 125 & 170 & 45 & 0.16 & 0.22 & 0.06 \\
Settlement & 1124 & 3790 & 2666 & 1.46 & 4.91 & 3.5 \\
\hline
\end{tabular}

Note; +ve Value indicates the area and the corresponding percentage rise; whereas, -ve Value indicates the area and the corresponding percentage downfall.

\section{Discussion}

The change in landuse/landcover in Walmara district has showed inconsistent pattern over the past thirty years. The landuse types such as, crop land and settlement have showed an increment in terms of the area, while grassland and wetland have dramatically shrunk. The area increment for the crop land use may emanate from the extensive crop production system of the area triggered not only by rapid population growth but also by the potentiality of the central highland of Ethiopia for the extension of crop production system [10].

In this connection, the farmers in the district might have expanded their farmland to the surrounding grassland areas with the desire of producing more crop yields to feed their family since during this period their farm lands were taken 
over by the government for investment purpose including floriculture industry.

The areas occupied by settlements in the district in 1985 has increased by threefold in 2017 and the likely reason for such increase could be due to illegal settlement and migrating from other regions of the country attracted by the job opportunities opened by investments on floriculture and other factories in the district. Unlike, cropland and settlement of the district, the forests cover and area of wetland has showed decreasing trends, but with low magnitude, with an area size $0.4 \%$ and $0.3 \%$ respectively over the past thirty years (Table 3). Likely, the reason for such insignificant change mainly for forest cover is that during the past decades massive Eucalyptus plantation has been undertaken by farmers and others to generate cash income from selling eucalyptus wood products [20].

Moreover, the increased emphasis and efforts on forest protection and development by both government and nongovernment organizations from time to time might have also contributed to the slow change of the forest cover in the study area. Such slow change in forest cover has also positively impacted the water body and wetland resources in the district.

\section{Conclusion}

Unlike forest cover, water bodies and wetlands, the landuse types such as, cropland, grassland and settlements have dramatically changed, but in different ways. The present study has added to our insight that the changes in land cover of different landuse types did not take similar pattern since the change in one landuse type is favored at the expense of the other landuse type (for example, compare grassland vs. settlement or cropland vs. forest land). Therefore, land managers and conservationists would give due emphasis on understanding how the spatiotemporal changes among different landuse types are related and act accordingly on devising landuse plan, agricultural production and conservation strategies.

\section{References}

[1] Al-sharif AA, Pradhan B. (2013). Monitoring and predicting land use change in the Tripoli Metropolitan City using an integrated Markov chain and cellular automata models in GIS. Arab J Geosci 7: 4291-4301.

[2] Ayalew D, Kassahun D, Woldetsadik M., 2012. Detection and analysis of land use and landcover changes in the Midwest escarpment of the Ethiopian Rift Valley. J Land Use Sci 7 (3): 239-260.

[3] Abate, S., 2011. Evaluating the land use and land cover dynamics in Borena woreda of south Wollo highlands, Ethiopia. J Sustain Dev Afr 13 (1): 87-105.

[4] Coppin, P. R., and Bauer, M. E., 1996. Digital change detection in forest ecosystems with remote sensing imagery. Remote sensing reviews, 13 (3-4), pp. 207-234.
[5] Eastman, J. R. 2003. Guide to GIS and Image Processing 14, 239-247. Clark University Manual, USA.

[6] Ebrahim EA, Mohamed A., 2017. Land use/cover dynamics and its drivers in Gelda catchment, Lake Tana watershed, Ethiopia. Environ Syst Res 6 (4): 1-13.

[7] Ellis, E. \& Pontius, R., 2007. Land use and land cover change. In C. J. Cleveland (Ed.), Encyclopedia of Earth. Washington, D. C.: Environmental Information Coalition, National Council for Science and the Environment. Retrieved July 29, 2010.

[8] Eshetu, Z. and Hogberg, P. 2000. Reconstruction of forest site history in Ethiopian highlands based on $\mathrm{C} 13$ natural abundance of soils. Ambio (29): 83-89.

[9] Fazal S, Amin A 2011. Impact of Urban Land Transformation on Water Bodies in Srinagar City, India. J Environ. Protection 2 (2): 142-153.

[10] Gebrehiwet, K. B., 2004. 'Land Use and Land Cover Changes in the Central Highlands of Ethiopia: the Case of Yerer Mountain and Its Surroundings', June, p. 147.

[11] Gessesse D, and Kleman J., 2007. Pattern and magnitude of deforestation in the South Central Rift Valley Region of Ethiopia. Mt Res Dev 27: 162-168.

[12] Hailemariam, SN. Teshome, S and Teketay D., 2016. Land use and land cover change in the Bale Mountain Eco-Region of Ethiopia during 1985 to 2015. Land 5: 41 McGinley, M. (2008). "Ethiopian montane moorlands." In C. J. Cleveland (Ed.), Encyclopedia of Earth. Washington, D. C: Environmental Information Coalition, National Council for Science and the Environment Retrieved August 20, 2010.

[13] Kindu M, Schneider T, Teketay D, Knoke T, 2013. Land use/land cover change analysis using object-based classification approach in Munessa Shashemene landscape of the Ethiopian highlands. J Remote Sens 5: 2411-2435.

[14] Lu, D. and Weng, Q., 2007. A survey of image classification methods and techniques for improving classification performance. International Journal of Remote sensing, 28 (5), pp. 823-870.

[15] Molla MB, 2014. Land use/land cover dynamics in the central Rift Valley region of Ethiopia: the case of Arsi Negele District. Acad J Environ Sci 2 (5): 074-088.

[16] Msoffe FU, Kifugo SC, Said MY, Neselle MO, Gardingen PV, Reid RS, Ogutu JO, Herero M, de Leeuw J, 2011. Drivers and impacts of land-use change in the Maasai Steppe of northern Tanzania: an ecological, social and political analysis. J Land Use Sci 6 (4): 261-281.

[17] Pontius Jr, R. G. and Millones, M., 2011. Death to Kappa: birth of quantity disagreement and allocation disagreement for accuracy assessment. International Journal of Remote Sensing, 32 (15), pp. 4407-4429.

[18] Tefera M, 2011. Land-use/land-cover dynamics in Nonno District, Central Ethiopia. J Sustain Dev Africa 13 (1): 123141.

[19] Teferi, E., Uhlenbrook, S., Bewket, W., Wenninger, J. and Simane, B., 2010. The use of remote sensing to quantify wetland loss in the Choke Mountain range, Upper Blue Nile basin, Ethiopia. Hydrology and Earth System Sciences, 14 (12), pp. 2415-2428. 
[20] Teketay, D., Lemenih, M. Tesfaye, B., Yonas, Y., Sisay F., Wubalem, T., Yitebetu, M., Tesfaye H., Demeke, N. 2010. Forest resources and challenges of sustainable forest management and conservation in Ethiopia. In: F. Bongers, T. Tennigkeit, and eds. degraded forests in Eastern Africa: management and restoration, 19-64. London: Earthscan.
[21] Temesgen G, Amare B, Abraham M., 2014 (a). Evaluation of land use/land cover changes and land degradation in Dera District, Ethiopia: GIS and remote sensing based analysis. Int J Sci Res Environ Sci 2 (6): 199-208. 